\title{
Socio-demographic Profile and Outcomes of the Admitted AIDS Patients in BPKIHS
}

\author{
Mehta R S. ${ }^{1}$, Singh B2
}

${ }^{1}$ Asst. Professor

Medical-Surgical Nursing Department

2Nursing Officer

B. P. Koirala Institute of Health Sciences, Nepal

Abstract: In world More than 40 million people are living with HIVIAIDS, 2.3 million are under 15 yrs , 14000 new infections each day , 1.7 million human infected with HIVIAIDS, 3.1 million deaths from AIDS, Million new HIV cases (13425) per day. In south East Asia 6.3 million PLWHA in 2005 (Source: WHO, UNAIDS).

It was retrospective descriptive study design conducted at B. P. Koirala Institute of Health Sciences (BPKIHS) among the admitted AIDS cases using their case notes during the period of 1-9-2003 to 30- 8-2006 using developed Performa. It was found that Majority of the subjects (83.4\%) were of age group 20-40 years, Male (89.6\%), and from Sunsari district (47.9\%). Half of the subjects were improved after treatment and then discharged.

As the number of AIDS cases are increasing rapidly in eastern Nepal and BPKIHS is a centre for treatment of AIDS cases, it is essential to conduct awareness activates regarding prevention of disease and advocacy about available facilities of BPKIHS.

Key words: AIDS, Socio-demographic profile, BPKIHS

\section{Correspondence to:}

Dr. Ram Sharan Mehta

Asst. Professor

Medical-Surgical Nursing Department

B. P. Koirala Institute of Health Sciences, Nepal

Email: ramsharanmehta@yahoo.com

\section{Introduction}

In Nepal the estimated number of PLWHA at end 2005 is 61,000 , HIV prevalence in 2005 was 0.5 , estimated number of AIDS cases are 7,800 , number of child $(0-18)$ orphaned by HIVIAIDS is 18000, receiving Ant Retroviral Treatment (ART) till December 2005 was 210. HIV infection has taken root in South Asia and poses a threat to development and poverty alleviation efforts in the region. HIV infection is fueled by risk behavior, extensive commercial sex, low condom use and access, injecting drug use, population movements (cross-border/ruralurban migration), and trafficking. ${ }^{1}$ 
Social and economic vulnerabilities, including poverty and illiteracy, highlight the need to act effectively and aggressively to reduce it's spread. South Asia has about 4.2 million of the world's 36 million people living with HIVIAIDS. While overall prevalence rates remain relatively low, the region's large populations mean that a rise of a mere 0.1 percent in the prevalence rate in India, for example, would increase the national total of adults living with HIV by about half a million persons. ${ }^{2}$

The current situation of HIV in Nepal is different from when the first case was diagnosed in 1988. There are gaps and challenges to be addressed in the fight against HIV and AIDS. Nepal is low prevalence country for HIV and AIDS. However, some of the groups show evidence of a concentrated HIV epidemic e.g. sex workers (19.5\%), migrant population (4-10 $\%$ ), and intravenous drug users (IVDU's) both in rural and urban areas (68\%). Since 1988 when the first case was diagnosed MoHP/DoHS and different stakeholders came forward to address HIV and AIDS issues. ${ }^{1}$

A significant percentage (60\%), of HIV positive patients belongs to lower socioeconomic class and many of them were mobile workers and contracted their illness while working in Indian metropolis in the past reported by Aich 5 in their study.

Study conducted by Agrwal $^{6}$ reported that there was a significant difference in the domain concerning social relationship between the HIV positive individuals with the controls.

Study conducted by Parakh ${ }^{7}$ at BPKIHS among the health professionals showed that health professionals had a hesitation in treating patients with HIVIAIDS, tempered by concerns regarding provision of such care.
Study conducted by Asrath ${ }^{10}$, among migrant workers in eastern Nepal found that, majority of migrant workers (94.9\%) had heard of HIVIAIDS, but only few know the symptoms of HIDS. Most of them aware that use of condom prevent spread of HIVIAIDS but $25 \%$ of them do not use, while having pre/extra marital sex. About $11.9 \%$ workers were going to sex workers at a regular intervals and no one using condoms.

HIVIAIDS is emerging as a major threat in the socio-economic and health sectors of Nepal. Their multiple effects have so far been minimal in the country, but their potential impact is immense.

\section{Objectives}

To find out the socio-demographic profile and outcomes of the admitted AIDS patients in B. P. Koirala Institute of Health Sciences.

\section{Methods}

It was retrospective descriptive study design, conducted at BPKIHS among the admitted AIDS clients. The available Case-sheets of the diagnosed AIDS cases admitted between $1^{\text {st }}$ September 2003 to 30th August 20006 constituted the population of the study. All the case notes of diagnosed discharged AIDS cases are samples and total 48 available case notes were included in the study. Using total enumerative sampling technique all the case notes were collected from the medical record section using coded numbers (B 24, ICD-10) of files after taking written permission from the hospital director. The files not available and incomplete were excluded. Using standard semi structured Performa the data was collected.

A list of diagnosed AIDS cases were prepared using coded index (ICD-10, Code-B 
24) files and than case notes were collected from record section and information were collected in the prepared format. All the case notes from September 1, 2003 to August 30, 2006 i.e. Bhadra 15, 2060 to Bhadra 14, 2063 were studded. Anonymity of the subjects was maintained. The information obtained was kept confidential and used only for this study. The collected data was entered in SPSS-10.5 software package and analyzed. The findings are presented in tables and graphs. Using Percentage, Mean and SD the demographic findings and outcomes were described.

\section{Results}

The number of AIDS cases admitted in BPKIHS is increasing day by day i.e. 10,12 \& 16 in the years 2061, 2062, and 2063 respectively as per the record but actual number is much more because the files are coded on the basis of written diagnosis on the admission discharge sheet, which was usually accurately filled and only the admitted diagnosis is mentioned. Now, BPKIHS is a centre for treatment of AIDS cases of Eastern Nepal, where the facilities of HIV testing, ART, PMTCT, VCT, and regular OPD services are available. Among all the 48 subjects, majority of them (83.3\%) were of age group 20-40 years Male (89.6\%), Mangolian (50\%), from Sunsari district (47.9\%) and among those $50 \%$ were improved and discharged from the hospital.

The details of the findings are depicted in Table-I.
Table I Socio-Demographic Profile and Outcomes of the Admitted AIDS Patients in BPKIHS ( $\mathrm{N}=48)$

\begin{tabular}{|c|c|c|}
\hline $\begin{array}{l}\mathrm{S} \\
\mathrm{N}\end{array}$ & Item/Particular & $\begin{array}{c}\text { Percentage } \\
(\%)\end{array}$ \\
\hline \multirow[t]{8}{*}{1} & Age group of the subjects: & \\
\hline & $<20$ years & 8.3 \\
\hline & 20-30 years & 48.0 \\
\hline & $30-40$ years & 35.4 \\
\hline & $>40$ years & 8.3 \\
\hline & Mean & 29.26 \\
\hline & SD & 9.4 \\
\hline & Range & 2-50 Years \\
\hline \multirow[t]{3}{*}{2} & Gender: & \\
\hline & Male & 89.6 \\
\hline & Female & 10.4 \\
\hline \multirow[t]{5}{*}{3} & Caste of the subjects: & \\
\hline & Brahmin/ Chetri & 29.2 \\
\hline & Mangolian & 50.0 \\
\hline & Newar & 2.1 \\
\hline & Teri Origin & 18.8 \\
\hline \multirow[t]{6}{*}{4} & $\begin{array}{l}\text { District Wise distribution } \\
\text { of the subjects: }\end{array}$ & \\
\hline & Sunsari & 47.9 \\
\hline & Morang & 18.8 \\
\hline & Jhapa & 14.6 \\
\hline & Sirha & 4.2 \\
\hline & $\begin{array}{l}\text { Others: ( Mahotari, } \\
\text { Dhankuta, Dhanusa, Ilam, } \\
\text { Taplagunj, Udapur) }\end{array}$ & 10 \\
\hline \multirow[t]{8}{*}{5} & $\begin{array}{l}\text { Duration of } \\
\text { hospitalization: }\end{array}$ & \\
\hline & $<5$ days & 41.7 \\
\hline & 5-10 days & 29.1 \\
\hline & $10-15$ days & 20.9 \\
\hline & $>15$ days & 8.3 \\
\hline & Mean & 7.98 \\
\hline & SD & 5.32 \\
\hline & Range & $1-28$ days \\
\hline \multirow[t]{4}{*}{6} & $\begin{array}{l}\text { Department wise } \\
\text { distribution of the } \\
\text { subjects: }\end{array}$ & \\
\hline & Medicine & 89.6 \\
\hline & Pediatric & 6.3 \\
\hline & Surgical & 4.2 \\
\hline \multirow[t]{7}{*}{7} & Outcome of the clients: & \\
\hline & Improved \& discharged & 50.0 \\
\hline & Unchanged \& discharged & 22.9 \\
\hline & Expired & 14.6 \\
\hline & LAMA & 8.3 \\
\hline & Discharge on Request & 2.0 \\
\hline & Absconded & 2.0 \\
\hline
\end{tabular}




\section{Discussion}

The report on the pattern of demographic and clinical profiles of HIV positive persons in Nepal are scarce. ${ }^{5}$ HIVIAIDS is rapidly spreading in countries of Asia including Nepal. It could cause major socio-economic impact in the country. It obviously has many health implications. ${ }^{9}$ HIVIAIDS is a growing public health problem with complex social and behavioral issues related to protection, prevention of transmission and care for nursing and midwifery personnel caring for people living with HIVIAIDS. ${ }^{8}$

\section{Demographic Profile of the subjects}

Majority of the clients were of age group of 20-40 years i.e. $83.4 \%$, which is similar pattern with national as well as international trends. Majority of clients were male (89.6\%) though the disease has equal prevalence. This low reporting may be due to social stigma and ignorance of diseases among female. Majority of the clients were Mangolian (50\%), as the hospital is situated in Dharan, where IVDUs are endemic, major occupation of these groups of people are lahure, and majority of people residing in Dharan are Mangolian. Similar demographic data were reported by Agrwal. ${ }^{6}$

Most of the clients were from Sunsari (47.9\%), Morang (18.8\%), and Jhapa $(14.6 \%)$, as BPKIHS is situated in Dharan which is easily arrival by the population of these three districts and there are three municipalities are in Sunsari, one is Morang, and two in Jhapa. Most of the clients are admitted under medicine department (89.6\%) as the disease is cared by doctors of medicine departments being adult patients.

\section{Outcomes of the clients}

Half of the clients were improved with the symptoms and discharged, where as $22.9 \%$ were unchanged. The disease is not curable but treatable; hence life long treatment is required along with management of opportunistic infections if occurred. The symptoms persist and client will die if the disease is not diagnosed in early stage and treatment (ART) started on time.

\section{Conclusions}

HIVIAIDS is no longer only a health issue; it is also a development issue. Tackling the epidemic will require not only prevention and control of HIV infection among vulnerable and risk groups, but a multi-sectoral approach addressing the lack of access by risk groups to health care and education and recognition of the populations at risk. People living with HIV and AIDS should be brought to the forefront in the fight against HIVIAIDS. Family members, local communities, civil society organizations, donors, and government all have their own important role to play. Increasing trend of the disease certainly has given pressure to focus on the use of comprehensive targeted intervention programs in risk groups sub-populations.

AIDS is a treatable disease, which is common among age groups of 20-40 years of their productive life. If proper treatment and care is provided the life of the clients can be prolonged with comfort. Keeping the emerging trends in mind it's mandatory to provide pubic awareness regarding the nature of disease, prevention of further spread and advocacy about availability of services and their utilization among the public like: HIV testing, screening OPD, VCT, PMTCT, ART, Management of opportunistic infection, CD-4 count services and other services of HIVIAIDS available at 
BPKIHS along with elimination of social stigma so that clients can approach easily at hospital and will be benefited with available facilities.

\section{References}

1. AIDS News letter: Quarterly (2061; Asoj). Women, Girls, HIV \& AIDS, 53:13-17.

2. Bhardwaj, A., Biswas, R., \& Shetty, K.J. (2001) HIV in Nepal: Is it rarer or the tip of an iceberg? Trop Doct, 31: 211-213.

3. WHO, SERO (1992). Carrying out HIV Sentinel Surveillance.

4. Vithayachockitikhum, N. (2006) Family caregiving of persons living with HIVIAIDS in Thailand. Caregiver burden, an outcome measure. International Journal of Nursing Practice; 12(3): 12

5. Aich TK, Dhungana M, Kumar A, Pawha VK. Demographic and clinical Profiles of HIV positive cases: A Two-year study report from a tertiary teaching Hospital. JNMA, 2004, 43(153).
6. Agrwal $H$, Mourya R, Shrestha RK, Agrwal $S$, Singh GK. Assessment of quality of life of HIV positive individuals at Dharan Municipality, 13th annual celebrations scientific programme abstract book, 2006, Dharn, Nepal.

7. Parakh P, Gupta G, Rizal S. HIVIAIDS related knowkedge, attitudes and risk perception amongst health professionals in BPKIHS. 13th annual celebrations scientific programme abstract book, 2006, Dharn, Nepal.

8. Impact of HIVIAIDS on Nursing /Mideifery personnel. ICN Positin( www.ich.ch).

9. Acharya RP, Bhattari MD. HIVIAIDS prevention and control. J. Nep. Med. Asso. 1999: 38: 106-108.

10. Asrath U, Sah S, Jha N etal. Awareness and high risk behaviours among migrant workers in relation to HIVIAIDS- a study from eastern Nepal. SAARC Journals of tuberculosis, lung diseases and HIVIAIDS. 2006; III(1): 5-12.

11. Joshi $A B$, Banjara MR, Karki YB, Subedi $B K$, Sharmam M. Status and trends of HIVIAIDS epidemic in Nepal. JNMA 2004; 43(152). 